\title{
Structure Control of a New-type High-Cr Superalloy
}

\author{
Jianxin Dong ${ }^{1}$, Zhongnan $\mathrm{Bi}^{1}$, Ning Wang ${ }^{2}$, Xishan Xie ${ }^{1}$, Zhigang Wang ${ }^{3}$ \\ ${ }^{1}$ University of Science and Technology Beijing; Beijing, 100083, China \\ ${ }^{2}$ Special Steel Branch, Baoshan Iron \& Steel Co., Ltd.; Shanghai, 200940, China \\ ${ }^{3}$ Northeast Special Steel Group Co., Ltd.; Fushun, Liaoning, 113001, China
}

Keywords: $\alpha-\mathrm{Cr}$ phase, High-Cr superalloy, Structure control

\begin{abstract}
High-Cr superalloys are a new class of nickel-based superalloys with more than $30 \% \mathrm{Cr}$, that has greater oxidation resistance than traditional superalloys. This paper compares the $\alpha-C r$ precipitation behavior in different $\mathrm{Cr}$-containing superalloys. For two tested alloys with more than $37 \% \mathrm{Cr}, \alpha-\mathrm{Cr}$ phase precipitates directly from the austenitic matrix with various morphologies. Heat treatment studies were performed on these two alloys in order to show the precipitation behaviors of $\alpha-\mathrm{Cr}$ phase, and find an optimized microstructure distribution. Furthermore, the phenomenon and mechanism of poor hot-working ability for high$\mathrm{Cr}$ alloys are also discussed.
\end{abstract}

\section{Introduction}

$\mathrm{Cr}$ is the most important element in nickel-based alloys to prevent high temperature oxidation and corrosion [1]. Increasing $\mathrm{Cr}$ gives improved oxidation and sulfidation resistance in $\mathrm{Ni}-\mathrm{Cr}$ alloys as shown in Figure 1[2]. However, the increasing of $\mathrm{Cr}$ content will lead to a decline of mechanical properties and processability [2-4]; a Cr-rich phase, $\alpha-\mathrm{Cr}$ (BCC structure) can precipitate from the matrix, which has various morphologies [5-10]. There is a continued need for higher temperature, corrosion resistant alloys which can withstand more aggressive environment. High $\mathrm{Cr}$ nickel-based superalloys including 32\%-40\% $\mathrm{Cr}$ have been developed since the 1970 s (e.g. GH 648). When they are used as mechanical parts in the aerial engine under $900^{\circ} \mathrm{C}$, the oxidation resistance at high temperature is much better than traditional nickel-based superalloys [11,12]. The main precipitate of these alloys is well known, $\alpha-C r$ phase, which can be an advantageous phase with proper heat treatment. In addition, other high $\mathrm{Cr}$ alloys were developed as powerful corrosion resistant alloys, such as Inconel 690, Inconel 671, Haynes G35 and VDM33. These alloys are widely used in chemical processing, petrochemical, nuclear industry and fertilizer manufacture for protection in the most aggressive environments [13].

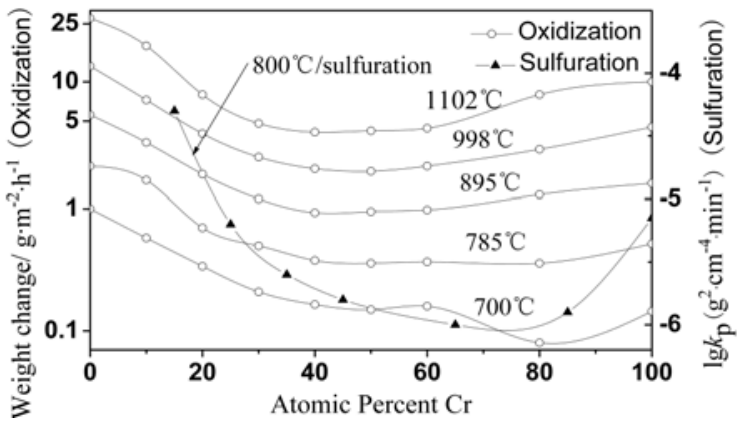

Figure 1. Oxidation and Sulfuration resistance of $\mathrm{Ni}-\mathrm{Cr}$ alloys as a function of $\mathrm{Cr}$ content [1]

However, quite limited information is available about the microstructural characteristics of high $\mathrm{Cr}$ superalloys. The author had done some preliminary investigations on different $\mathrm{Cr}$ containing superalloys, such as GH169, GH625, GH648 and two high-Cr superalloys with more than $37 \% \mathrm{Cr}$. Heat treatment studies were performed on the two tested alloys in order to show the precipitation behaviors of $\alpha-\mathrm{Cr}$ phase and find an optimized microstructure distribution. These results can also become the references for component design and heat treatment of high $\mathrm{Cr}$ superalloys.

On the other hand, forge processing property is not perfect for high-Cr superalloys because of its poor thermal plasticity. The ingot-batch ratio of hot forge-cogging for $30 \% \mathrm{Cr}-70 \% \mathrm{Ni}$ alloy is lower than $25 \%$. The present paper also will simulate hot forgecogging for a high-Cr tested alloy and search for causes of low hot working ability.

\section{Experimental Procedure}

To study the microstructural evolution of high-Cr superalloys, a serious of different Cr-containing alloys were prepared to characterize the microstructures after various thermal treatments. Table I lists the chemistries for all the tested alloys. GH169 was processed by VIM+ESR+VAR, GH625 and GH648 were processed by VIM+VAR, GH837 and GH840 were processed by VIM, followed by rolling directly. K648 is a cast superalloy.

SEM images of microstructures were revealed by mechanical polishing and electro-etching in a solution of $20 \% \mathrm{H}_{2} \mathrm{SO}_{4}-80 \%$ methanol at $25 \mathrm{~V}$. Tensile strength and stress rupture life were tested for some alloys.

Table I The chemical compositions of the tested alloys (wt \%)

\begin{tabular}{|c|c|c|c|c|c|c|c|c|}
\hline Alloy & $\mathrm{C}$ & $\mathrm{Cr}$ & $\mathrm{Mo}$ & $\mathrm{Ti}$ & $\mathrm{Al}$ & $\mathrm{Nb}$ & $\mathrm{W}$ & $\mathrm{Fe}$ \\
\hline GH169 & 0.021 & 17.89 & 2.99 & 0.94 & 0.49 & 5.36 & - & 18.05 \\
\hline GH625 & 0.014 & 21.8 & 9.02 & 0.26 & 0.19 & 3.53 & & 4.17 \\
\hline GH648 & 0.057 & 32.96 & 2.84 & 1.02 & 1.05 & 0.91 & 4.57 & - \\
\hline K648a & 0.06 & 33.36 & 2.87 & 1.14 & 1.14 & 1.06 & 4.76 & - \\
\hline K648b & 0.07 & 33.18 & 2.81 & 1.13 & 1.15 & 1.05 & 4.74 & - \\
\hline K648c & 0.06 & 33.37 & 2.79 & 1.14 & 1.11 & 1.05 & 4.74 & - \\
\hline K648d & 0.06 & 33.25 & 2.76 & 1.17 & 1.12 & 1.06 & 4.68 & - \\
\hline GH837 & 0.009 & 37.02 & - & 2.79 & 2.01 & - & - & - \\
\hline GH840 & 0.01 & 40.0 & - & - & 3.34 & - & - & - \\
\hline
\end{tabular}

* Ni balance;

\section{Results}

$\underline{\alpha-C r}$ precipitation behavior in different $\mathrm{Cr}$ containing alloys

$\alpha$-Cr phase was identified in stainless steel as the origin of " $475^{\circ} \mathrm{C}$ brittleness". For nickel-based superalloys with less than $30 \% \mathrm{Cr}$ (GH169 and GH625), no $\alpha$-Cr phase was observed after standard heat treatment, but with long-term aging $\alpha$-Cr phase precipitates. It grows usually adjoining $\delta$ phase in $\mathrm{GH} 169$ alloy, adjoining $\mathrm{M}_{6} \mathrm{C}$ carbide and $\delta$ phase in GH625 alloy (Figure 2(a),(b)). Because of its BCC structure, it is commonly believed that $\alpha-\mathrm{Cr}$ is a brittle phase which may be harmful for the mechanical properties. 

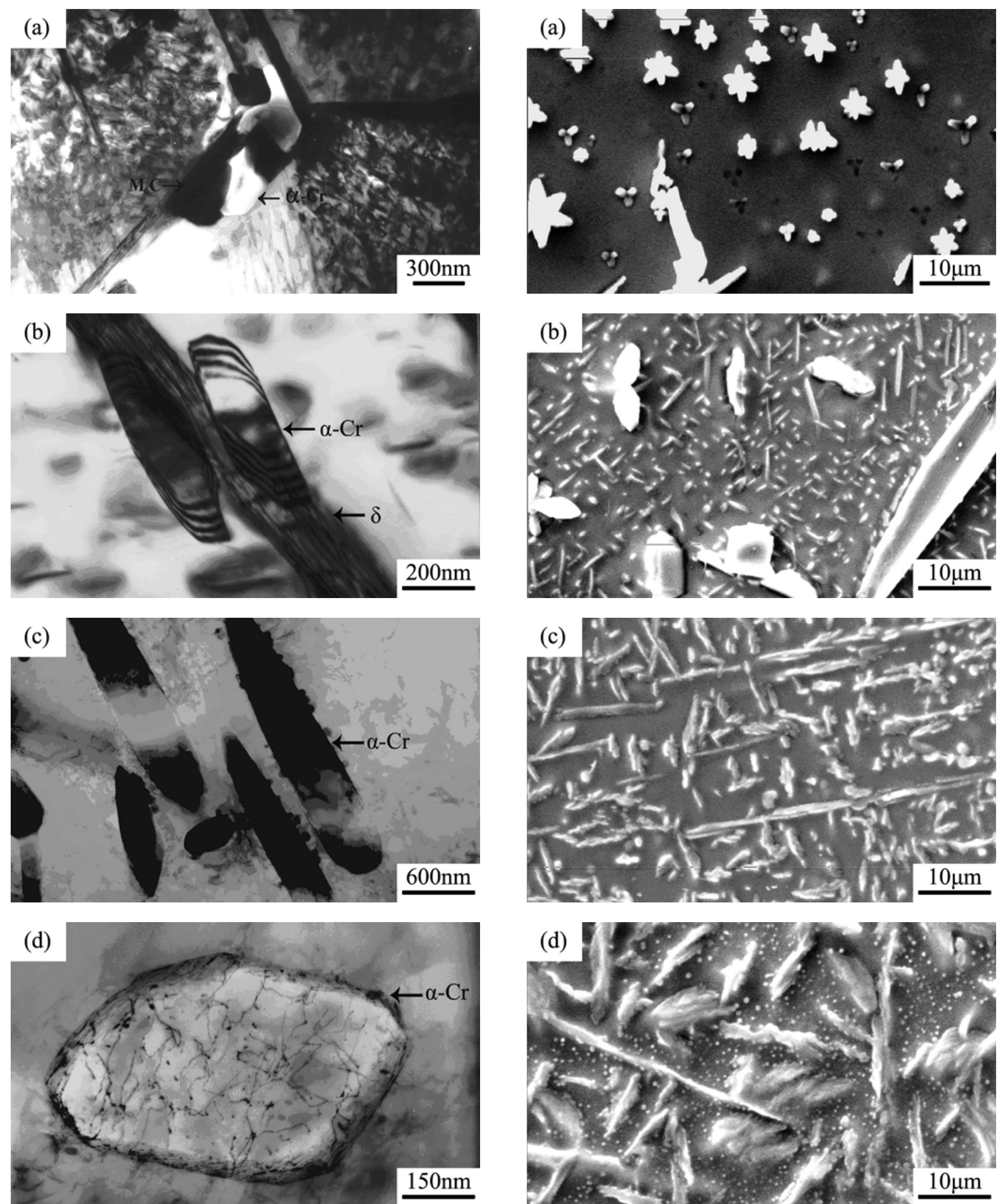

Figure 2. TEM morphologies of $\alpha-\mathrm{Cr}$ phase in the different $\mathrm{Cr}$ containing alloys

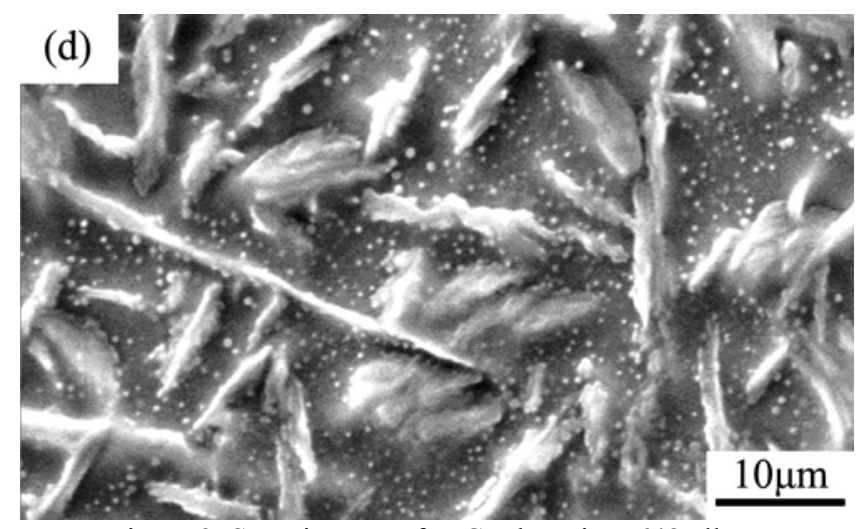

Figure 3. SEM images of $\alpha$-Cr phase in K648 alloys *corresponding compositions in Table I

(a) GH625 after $650^{\circ} \mathrm{C} / 5000 \mathrm{~h} \quad$ (b) $\mathrm{GH} 169$ after $677^{\circ} \mathrm{C} / 2000 \mathrm{~h}$ (c)(d) $\mathrm{GH} 648$ after $1140^{\circ} \mathrm{C} / 1 \mathrm{~h} / \mathrm{AC}+900^{\circ} \mathrm{C} / 16 \mathrm{~h} / \mathrm{AC}$ 
However, for high-Cr superalloys (GH648, GH837 and GH840), $\alpha-\mathrm{Cr}$ was the main precipitation phase during cooling. It precipitated directly from the austenitic matrix, with various morphologies. There existed many dislocations within $\alpha-\mathrm{Cr}$ particles in GH648 after standard heat treatment $1140^{\circ} \mathrm{C} \times 1 \mathrm{hAC}+900^{\circ} \mathrm{C} \times 16 \mathrm{hAC}$ (Figure $2(\mathrm{~d})$ ). These dislocations prove that the $\alpha-\mathrm{Cr}$ particle can be deformed and is not completely brittle.

The same phenomenon can be found in cast alloy K648 after the standard heat treatment. Figure 3 shows that $\alpha$-Cr precipitates directly from the austenitic matrix with various morphologies, with short-plates, star shapes and long acicular to lamellar shapes, arising from $\mathrm{Cr}$ content differences and possible differences in solidification cooling rate. From these observations we can conclude that in high-Cr alloys, the $\alpha-\mathrm{Cr}$ morphology is sensitive to composition changes and thermal treatments.
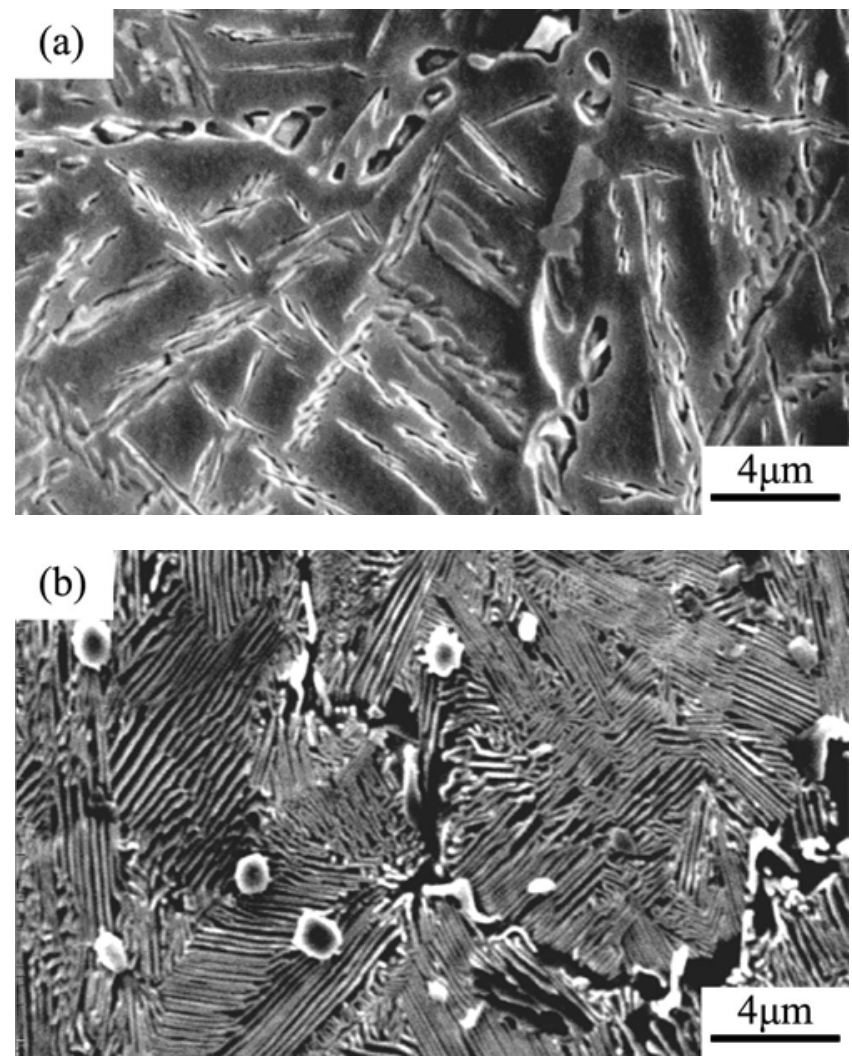

Figure 4. SEM images of $\alpha-\mathrm{Cr}$ in GH837 and GH840 as-rolled

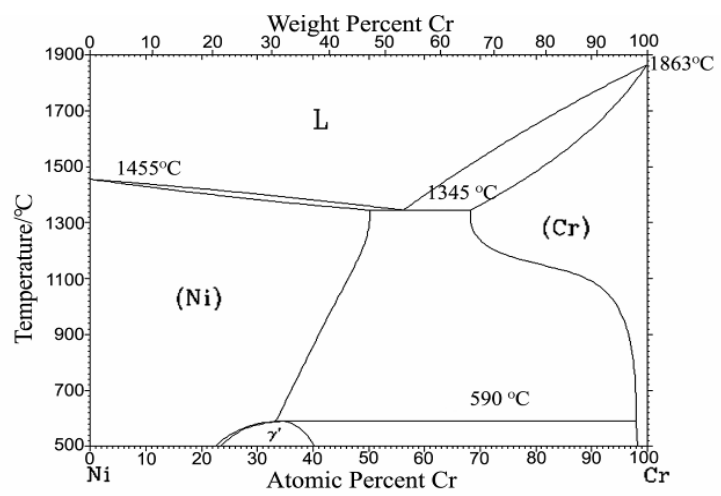

Figure 5. Phase diagram of Ni-Cr alloys
Yet, this also indicates that it could be possible to optimize $\alpha-\mathrm{Cr}$ structure. Namely, $\alpha-\mathrm{Cr}$ could be precipitated as small and dispersed particles or short-plates by proper heat treatment. Potentially $\alpha-\mathrm{Cr}$ could then be used as a beneficial phase in such high-Cr superalloys.

GH837 and GH840 are newly developed alloys with above $35 \%$ $\mathrm{Cr}$. The as-rolled structures of these two alloys are shown in Figure 4, with amounts of $\alpha$-Cr higher than GH648 because of their higher $\mathrm{Cr}$ contents. Most $\alpha-\mathrm{Cr}$ phase precipitates have long lamellar and acicular shapes.

The diverse morphologies of $\alpha$-Cr precipitates can be explained from Figure 5, the Ni-Cr phase diagram. The solid solubility of $\mathrm{Cr}$ in $\mathrm{Ni}-\mathrm{Cr}$ alloys has a sharp decline with decreasing temperature. This steep curve promotes various shapes of $\alpha-\mathrm{Cr}$ phase precipitates. It also brings the theoretic possibility for optimizing $\alpha-\mathrm{Cr}$ microstructure.

\section{$\underline{\text { Structure control of GH837 and GH840 }}$}

The precipitation characteristics of $\alpha-\mathrm{Cr}$ phase were studied in order to optimize the two new high-Cr tested alloys by proper heat treatments.

\section{Comparison between GH837 and GH648}

In order to find the correlation between the morphology of $\alpha-\mathrm{Cr}$ and mechanical performance, microstructure and mechanical properties are compared between GH837 and GH648 after the same heat treatment of $1140^{\circ} \mathrm{C} \times 1 \mathrm{hAC}+900^{\circ} \mathrm{C} \times 16 \mathrm{hAC}$.
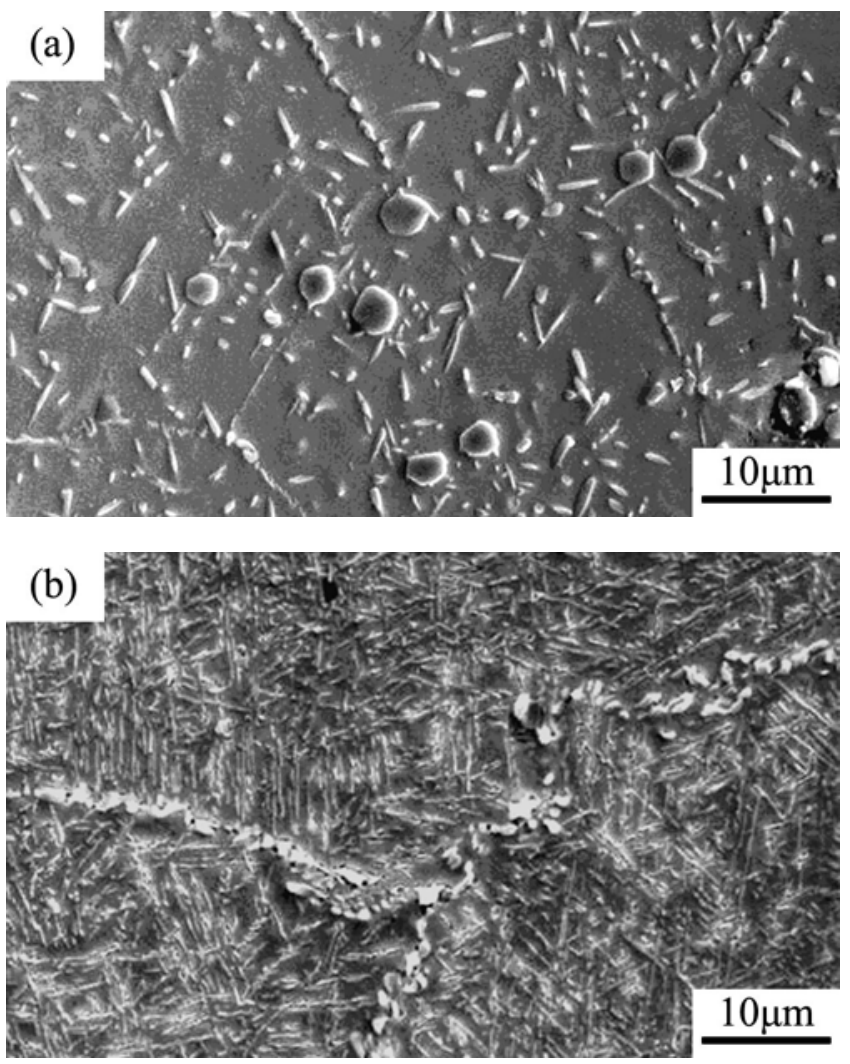

Figure 6. SEM images of $\alpha-\mathrm{Cr}$ phase after $1140^{\circ} \mathrm{C} / 1 \mathrm{~h} / \mathrm{AC}+900^{\circ} \mathrm{C} / 16 \mathrm{~h} / \mathrm{AC}$ (a)GH648 (b)GH837 
Table II The mechanical performances of GH648 and GH 837 after $1140^{\circ} \mathrm{C} \times 1 \mathrm{hAC}+900^{\circ} \mathrm{C} \times 16 \mathrm{hAC}$

\begin{tabular}{|c|c|c|c|c|c|c|c|c|c|c|c|}
\hline \multirow[b]{2}{*}{ Alloy } & \multicolumn{4}{|c|}{$20^{\circ} \mathrm{C}$} & \multicolumn{4}{|c|}{$800^{\circ} \mathrm{C}$} & \multicolumn{3}{|c|}{$800^{\circ} \mathrm{C}, 175 \mathrm{MPa}$} \\
\hline & $\begin{array}{c}\sigma_{\mathrm{b}} \\
\mathrm{MPa}\end{array}$ & $\begin{array}{c}\sigma_{\mathrm{s}} \\
\mathrm{MPa}\end{array}$ & $\begin{array}{c}\delta \\
\%\end{array}$ & $\begin{array}{l}\psi \\
\%\end{array}$ & $\begin{array}{c}\sigma_{\mathrm{b}} \\
\mathrm{MPa}\end{array}$ & $\begin{array}{c}\sigma_{\mathrm{s}} \\
\mathrm{MPa}\end{array}$ & $\begin{array}{c}\delta \\
\%\end{array}$ & $\begin{array}{l}\psi \\
\%\end{array}$ & $/ \mathrm{h}$ & $\begin{array}{c}\delta \\
\%\end{array}$ & $\begin{array}{l}\psi \\
\%\end{array}$ \\
\hline GH648 & 952 & 528 & 43.5 & 53.0 & 585 & - & 47.5 & 41.0 & 104.4 & 27.5 & - \\
\hline
\end{tabular}

$* \sigma_{\mathrm{b}}=$ ultimate tensile strength; $\sigma_{\mathrm{s}}=0.2 \%$ yield strength; $\delta=\%$ elongation; $\psi=\%$ reduction area

From Table II the compared mechanical properties indicate that the ductility and stress rupture life of high-Cr GH837 is much lower than GH648 after the same heat treatment. Their microstructures are shown in Figure 6. Most $\alpha-\mathrm{Cr}$ phase precipitate were dispersed in GH648 with small particle or shortplate morphology. GH837, with $\mathrm{Cr}$ content increasing from $33 \%$ to $37 \%$ has much more $\alpha-\mathrm{Cr}$ than GH648. Most $\alpha-\mathrm{Cr}$ phase precipitate in GH837 are acicular shape, and even form acicular nets in some regions. These unfavorable structures may cause the reduction of ductility and stress rupture life.

Therefore, in order to optimize the structure for high mechanical performance of these high-Cr type alloys, a series of thermal treatments were performed. The heat treatment optimization was divided into two parts, solution and aging. Solution treatments included full solutions to completely dissolve $\alpha$-Cr into the matrix, and partial solutions where most of $\alpha-\mathrm{Cr}$ is dissolved.

\section{Solution}
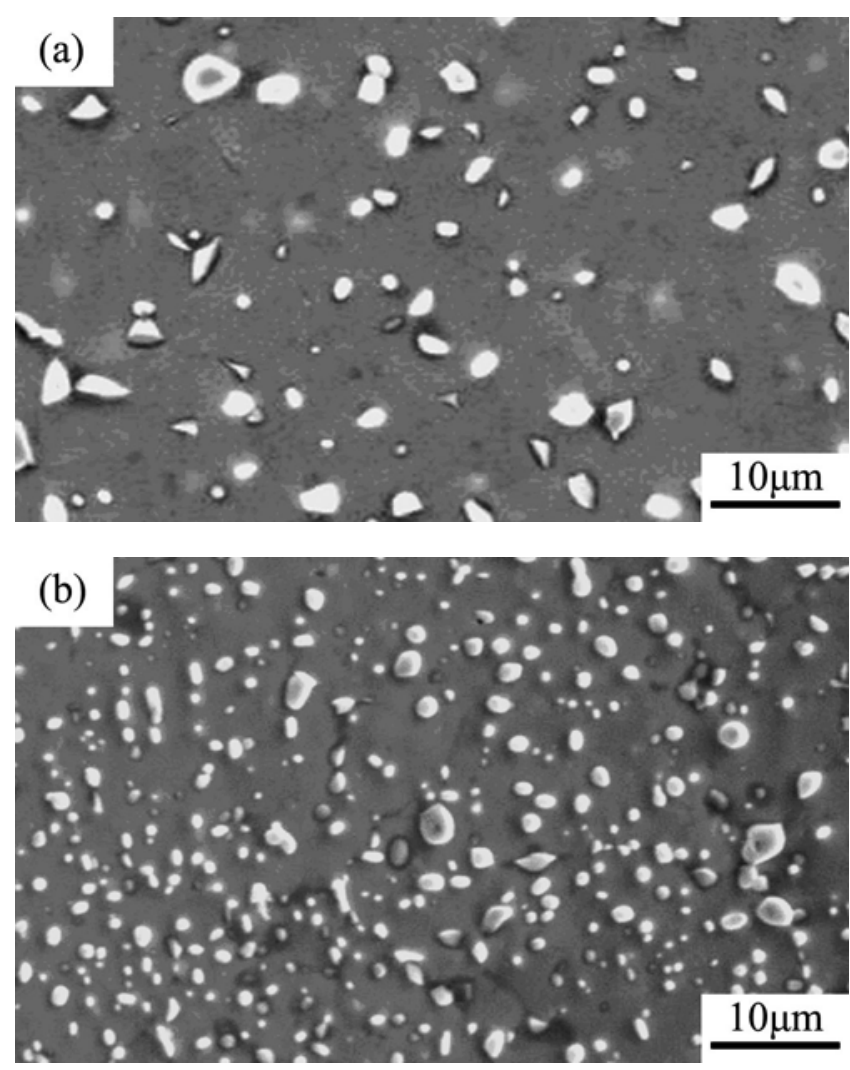

Figure 7. SEM images of $\alpha-\mathrm{Cr}$ phase after the partial solution of $1140^{\circ} \mathrm{C} / 30 \mathrm{~min} / \mathrm{WQ}$ (a)GH837 (b)GH840
In order to study the effect of solution temperature on $\alpha$-Cr precipitation, samples of $\mathrm{GH} 837$ and $\mathrm{GH} 840$ were treated at $1080^{\circ} \mathrm{C}, 1100^{\circ} \mathrm{C}, 1140^{\circ} \mathrm{C}, 1160^{\circ} \mathrm{C}, 1180^{\circ} \mathrm{C}, 1200^{\circ} \mathrm{C}, 1250^{\circ} \mathrm{C}$, $1300^{\circ} \mathrm{C}$ for $5 \mathrm{mins}, 10 \mathrm{mins}, 30 \mathrm{mins}$, $1 \mathrm{~h}$, then water quenched and air cooled. From these microstructure observations we deduced $\alpha-\mathrm{Cr}$ was fully dissolved at $1200^{\circ} \mathrm{C} \times 30 \mathrm{~min}$ for $\mathrm{GH} 837$ and $1250^{\circ} \mathrm{C} \times 2 \mathrm{~h}$ for $\mathrm{GH} 840$.

The partial solution treatment of $1140^{\circ} \mathrm{C} \times 30 \mathrm{~min}$ was selected, with Figure 7 demonstrating the primary long-acicular $\alpha$-Cr can be turned into dispersed and small sphere particles. Cooling of WQ or AC didn't strongly affect their microstructures.

\section{$\underline{\text { Aging after partial solution }}$}

Table III Aging treatments after partial solution

\begin{tabular}{|l|l|l|}
\hline Alloy & Solution & Aging \\
\hline GH837 & $1140^{\circ} \mathrm{C} \times 30 \mathrm{~min}$ & $700,750,800($ Fig.7a) $, 850,900$, \\
& WQ & $950^{\circ} \mathrm{C}($ Fig.7b $) \times 1 \mathrm{~h}$ WQ \\
\hline GH840 & $1140^{\circ} \mathrm{C} \times 30 \mathrm{~min}$ & $700,750,800($ Fig.7c) $, 850,900$, \\
& WQ & $950^{\circ} \mathrm{C}($ Fig.7d $) \times 1 \mathrm{~h}$ WQ \\
\cline { 3 - 3 } & & $950^{\circ} \mathrm{C} \times 2,5 \mathrm{~h}$ WQ \\
\hline
\end{tabular}

Although partial solution can obtain small, near spherical particles, it is not clear this structure is stable. Figure 8 shows the results of aging after partial solution. Additional $\alpha-\mathrm{Cr}$ precipitates preferentially along the prior $\alpha$-Cr. $\alpha$-Cr precipitates and grows slowly at low temperatures, but new $\alpha$-Cr precipitates from the matrix much faster at higher temperature. Further more, long lamellar $\alpha-\mathrm{Cr}$ structure could be found again (Figure 8(c)), which is possible because of the incompletely solution.

Aging after full solution

Table IV Aging treatments after full solution

\begin{tabular}{|l|l|l|}
\hline Alloy & Solution & Aging \\
\hline GH837 & $1200^{\circ} \mathrm{C} \times 30$ & $700^{\circ} \mathrm{C} \times 10,50,180,300 \mathrm{~h}$ WQ \\
\cline { 3 - 3 } & min WQ & $800^{\circ} \mathrm{C} \times 10,50,130($ Fig.8a), $200 \mathrm{~h}$ WQ \\
\cline { 3 - 3 } & & $900^{\circ} \mathrm{C} \times 1,5,10,15 \mathrm{~h} \mathrm{WQ}$ \\
\cline { 3 - 3 } & & $950^{\circ} \mathrm{C} \times 1,5,10,15 \mathrm{~h} \mathrm{WQ}$ \\
\cline { 3 - 3 } & & $1140^{\circ} \mathrm{C} \times 30 \mathrm{mins}$ (Fig.8c) WQ \\
\hline GH840 & $1250^{\circ} \mathrm{C} \times 2 \mathrm{~h}$ & $750,800,900^{\circ} \mathrm{C}($ Fig.8b) $\times 10 \mathrm{~h}$ WQ \\
\cline { 3 - 3 } & WQ & $1000^{\circ} \mathrm{C} \mathrm{(Fig.8d),1140}{ }^{\circ} \mathrm{C} \times 1 \mathrm{~h} \mathrm{WQ}$ \\
\hline
\end{tabular}

Table IV lists the aging conditions after full solution treatments. As shown in Figure 9, the precipitate microstructures after full solution plus aging are totally homogeneous, unlike partial solution+agings. But after long time aging at $800^{\circ} \mathrm{C}$ (Figure 9(a)), $\alpha-\mathrm{Cr}$ phase evolves into dense acicular networks in local regions. During higher temperature aging, Figure 9(c, d) shows that more dispersed, short and plate acicular precipitates can be obtained. 

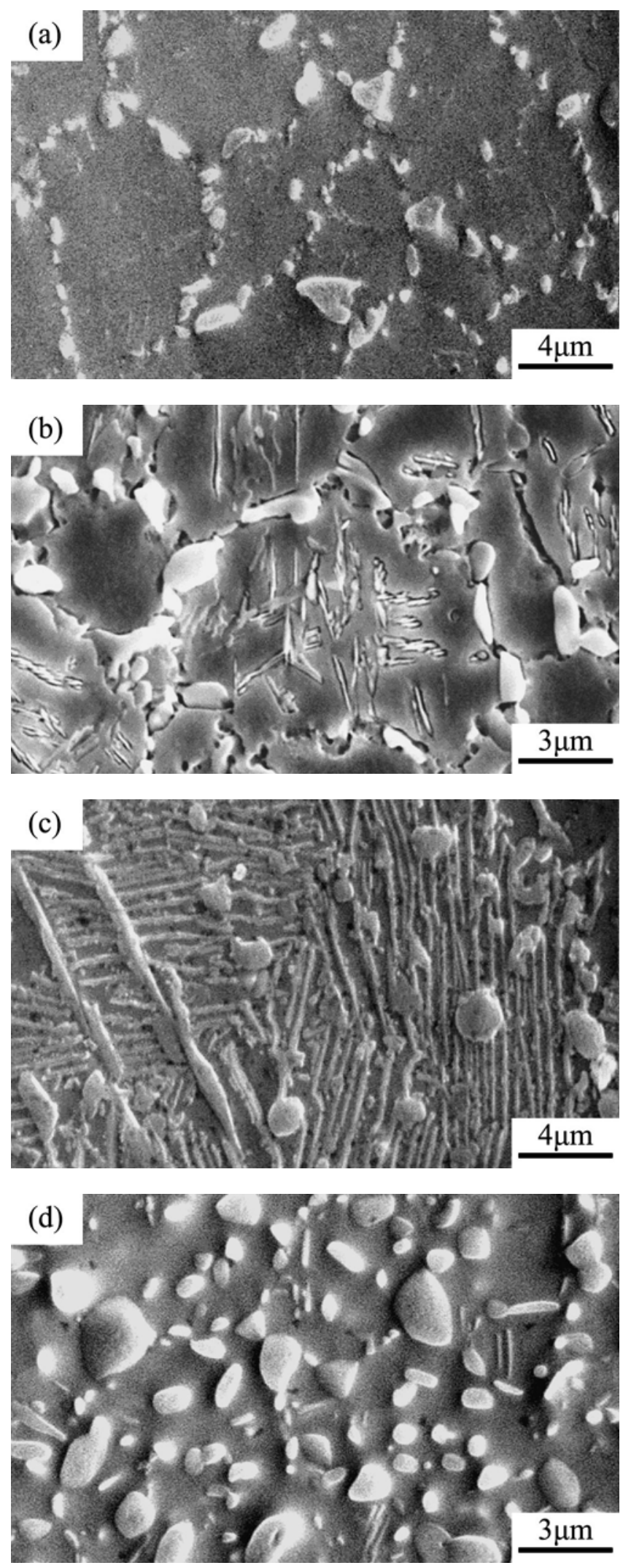

Figure 8. SEM images of $\alpha$-Cr phase after partial solution+aging+WQ (a) $\mathrm{GH} 837,800^{\circ} \mathrm{C}$; (b) $\mathrm{GH} 837,950^{\circ} \mathrm{C}$;

(c) $\mathrm{GH} 840,800^{\circ} \mathrm{C}$; (d) $\mathrm{GH} 840,950^{\circ} \mathrm{C}$

* corresponding HT condition in Table III
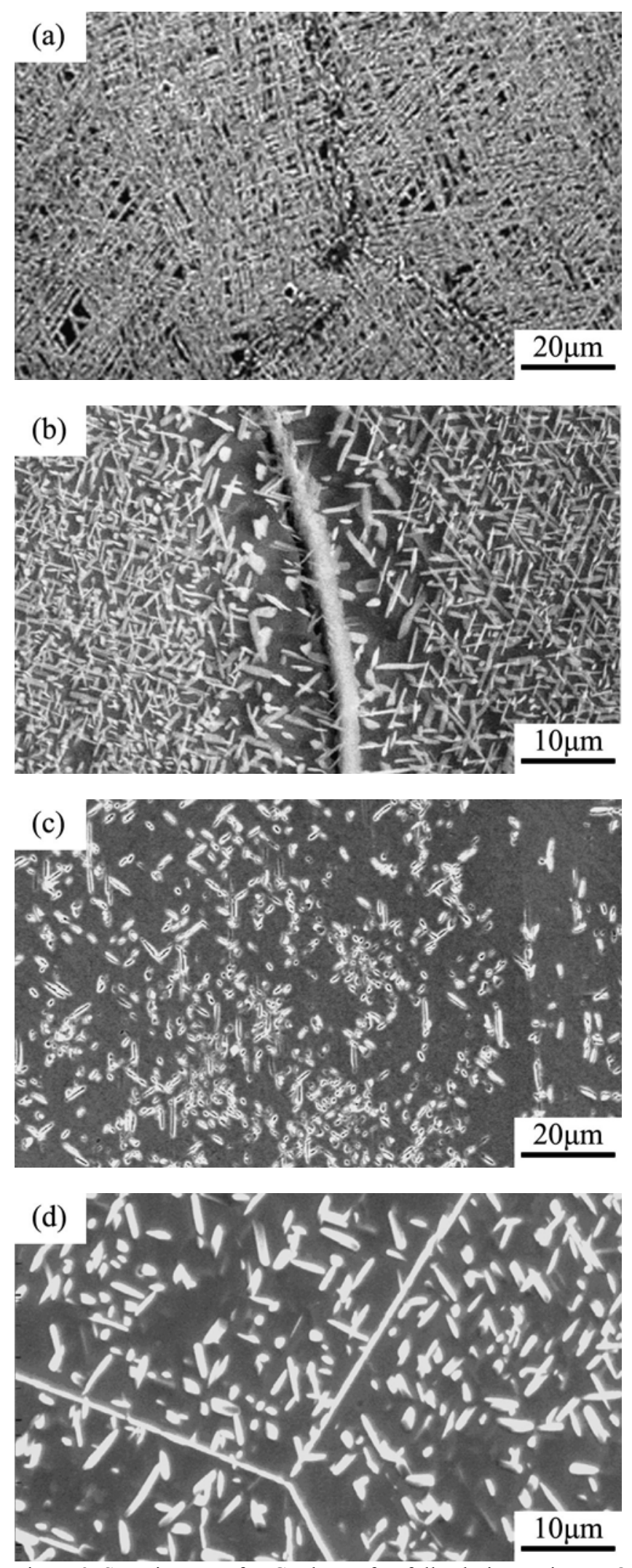

Figure 9. SEM images of $\alpha-\mathrm{Cr}$ phase after full solution+aging+WQ (a) $\mathrm{GH} 837,800^{\circ} \mathrm{C} / 130 \mathrm{~h}$; (b) $\mathrm{GH} 840,950^{\circ} \mathrm{C} / 10 \mathrm{~h}$; (c) $\mathrm{GH} 837,1140^{\circ} \mathrm{C} / 30 \mathrm{~min}$; (d) $\mathrm{GH} 840,1000^{\circ} \mathrm{C} / 1 \mathrm{~h}$ *corresponding HT condition in Table IV 


\section{Multiple Step Aging}

According to the above experimental results, the degree of $\mathrm{Cr}$ supersaturation in GH837 and GH840 is high and the corresponding amount of $\alpha-\mathrm{Cr}$ precipitation is quite great. Therefore, structure control of these high $\mathrm{Cr}$ alloys is difficult. Precipitation after only one step aging could not easily meet the requirements of both microstructural uniformity and structure stability. Consequently, multiple step aging treatments were performed, in order to form $\alpha$-Cr phase precipitates at different temperatures.

Table V Multiple step aging treatments for GH837 and GH 840

\begin{tabular}{|c|c|c|}
\hline Alloy & Solution & Aging \\
\hline \multirow[t]{3}{*}{ GH837 } & \multirow{3}{*}{$\begin{array}{l}1200^{\circ} \mathrm{C} \\
\times 30 \mathrm{~min} \\
\mathrm{WQ}\end{array}$} & $1140^{\circ} \mathrm{C} \times 30 \mathrm{~min} W \mathrm{~W}$ \\
\hline & & $+900^{\circ} \mathrm{C} \times 10,50,100,200 \mathrm{~h}$ WQ \\
\hline & & $\begin{array}{l}1140^{\circ} \mathrm{C} / 30 \mathrm{~min} W \mathrm{WQ}+900^{\circ} \mathrm{C} / 16 \mathrm{hWQ} \\
+800^{\circ} \mathrm{C} \times 0 \mathrm{~h}(\text { Fig.9a) }, 10,50,100,200 \mathrm{~h}(\text { Fig.9b }) \\
\text { WQ }\end{array}$ \\
\hline \multirow[t]{5}{*}{ GH840 } & \multirow{2}{*}{$\begin{array}{l}1250^{\circ} \mathrm{C} \\
\times 2 \mathrm{~h} \\
\mathrm{WQ}\end{array}$} & $\begin{array}{l}1140^{\circ} \mathrm{C} \times 30 \mathrm{~min} \mathrm{WQ} \\
+950^{\circ} \mathrm{C} \times 1,2,5,10,50,100,200 \mathrm{~h} \text { WQ }\end{array}$ \\
\hline & & $\begin{array}{l}1140^{\circ} \mathrm{C} \times 30 \mathrm{~min} \mathrm{WQ}+950^{\circ} \mathrm{C} \times 1 \mathrm{~h} \mathrm{WQ} \\
+830 \times 5 \mathrm{~h}(\text { Fig.10a }), 15,30 \mathrm{~h}(\text { Fig.10b }) \mathrm{WQ}\end{array}$ \\
\hline & \multirow[t]{2}{*}{$\begin{array}{l}1200^{\circ} \mathrm{C} \\
\times 2 \mathrm{~h} \\
\mathrm{WQ}\end{array}$} & $\begin{array}{l}1140^{\circ} \mathrm{C} \times 30 \mathrm{~min} \mathrm{WQ}+950^{\circ} \mathrm{C} \times 2 \mathrm{~h} \mathrm{WQ} \\
+800^{\circ} \mathrm{C} \times 1 \mathrm{~h}(\text { Fig.10c }), 2,5,10,50,100, \\
200 \mathrm{~h}(\text { Fig.10d }) \mathrm{WQ}\end{array}$ \\
\hline & & $\begin{array}{l}1140^{\circ} \mathrm{C} \times 30 \mathrm{~min} W \mathrm{WQ}+700^{\circ} \mathrm{C} \times 4 \mathrm{~h} \text { up to } \\
950^{\circ} \mathrm{C} \times 2 \mathrm{~h} \text { WQ } \\
+800^{\circ} \mathrm{C} \times 1 \mathrm{~h}(\text { Fig.10e) }, 2,5,10,50,100 \\
200 \mathrm{~h} \text { (Fig.10f) WQ }\end{array}$ \\
\hline & $\begin{array}{l}1140^{\circ} \mathrm{C} \\
\times 30 \mathrm{~min} \\
\mathrm{WQ}\end{array}$ & $\begin{array}{l}950^{\circ} \mathrm{C} \times 1 \mathrm{~h} \text { WQ } \\
+800^{\circ} \mathrm{C} \times 1 \mathrm{~h}(\text { Fig10g }), 5,10,50,100 \\
200 \mathrm{~h}(\text { Fig10h }), 250 \mathrm{~h} \text { WQ }\end{array}$ \\
\hline
\end{tabular}

In order to find a stable microstructure with long-time structure stability, multiple step aging treatments of high and intermediate temperature aging; plus $800^{\circ} \mathrm{C}$ exposures up to $200 \mathrm{~h}$ long time, were performed as listed in Table V. Corresponding microstructures are shown in Figure 10 and Figure 11. It can be seen that most $\alpha$-Cr precipitates as fine and small uniform particles and short-plates. Furthermore, after $800^{\circ} \mathrm{C} / 200 \mathrm{~h}$ aging,

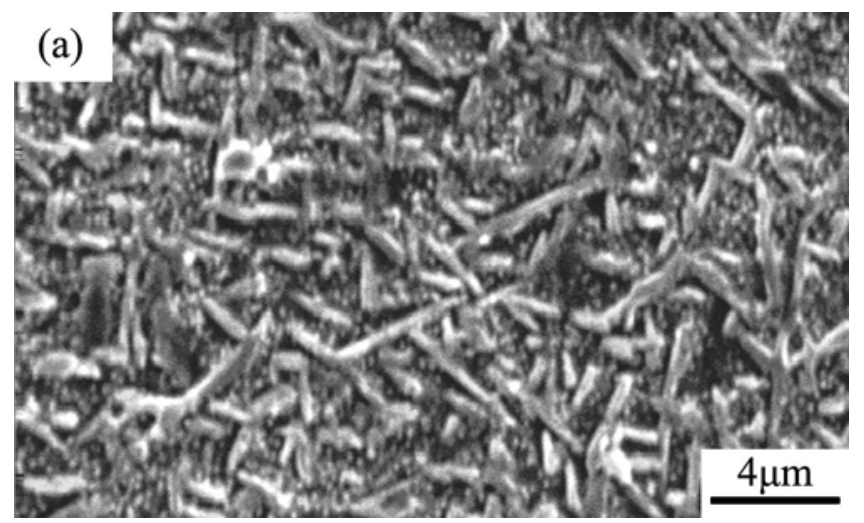

the structure appeared quite stable. Thus, it is apparent that $\alpha-\mathrm{Cr}$ in high-Cr alloys can give uniform and highly stable precipitate microstructures by utilizing proper heat treatment.

\section{Mechanical properties of GH837 after heat treatments}

Based on these results, two heat treatments were chosen for GH837 as shown in Table VI, and the mechanical properties were tested after the heat treatments. Table VII shows the results of mechanical property tests. Heat treatment B has very good results for both tensile strength and ductility at room temperature and $800^{\circ} \mathrm{C}$, while heat treatment $\mathrm{A}$ has poor ductility for the same alloy. This great distinction indicates the severe complexity and sensitivity of microstructure-property relationship for this type of high-Cr alloys. But comparing these GH837 tensile property results to those of a standard heat treatment of GH648 in Table II, multiple step aging enhance tensile ductility up to 2.5 times. This gives promise for obtaining high performance in high-Cr alloys by microstructure-property optimization.

Table VI Heat treatments for mechanical properties of GH837

\begin{tabular}{|l|l|l|}
\hline & Solution & Aging \\
\hline A & $1160^{\circ} \mathrm{C} \times 1 \mathrm{~h} \mathrm{AC}$ & $1140^{\circ} \mathrm{C} \times 30 \mathrm{~min} \mathrm{AC}+900^{\circ} \mathrm{C} \times 1 \mathrm{~h} \mathrm{AC}$ \\
\hline B & $1140^{\circ} \mathrm{C} \times 30 \mathrm{~min} \mathrm{AC}$ & $950^{\circ} \mathrm{C} \times 5 \mathrm{~h} \mathrm{AC}+850^{\circ} \mathrm{C} \times 1 \mathrm{~h} \mathrm{AC}$ \\
\hline
\end{tabular}

Table VII Tensile properties of GH 837 after two heat treatments

\begin{tabular}{|c|c|c|c|c|c|c|c|c|}
\hline \multirow{2}{*}{} & \multicolumn{4}{|c|}{$20^{\circ} \mathrm{C}$} & \multicolumn{4}{|c|}{$800^{\circ} \mathrm{C}$} \\
\cline { 2 - 9 } & $\begin{array}{c}\sigma_{\mathrm{b}} \\
\mathrm{MPa}\end{array}$ & $\begin{array}{c}\sigma_{\mathrm{s}} \\
\mathrm{MPa}\end{array}$ & $\begin{array}{c}\delta \\
\%\end{array}$ & $\begin{array}{c}\psi \\
\%\end{array}$ & $\begin{array}{c}\sigma_{\mathrm{b}} \\
\mathrm{MPa}\end{array}$ & $\begin{array}{c}\sigma_{\mathrm{s}} \\
\mathrm{MPa}\end{array}$ & $\begin{array}{c}\delta \\
\%\end{array}$ & $\begin{array}{c}\psi \\
\%\end{array}$ \\
\hline $\mathrm{A}$ & 1295 & 1120 & 4.0 & 5.9 & 532 & - & 5.3 & 4.7 \\
\hline $\mathrm{B}$ & 1340 & 970 & 20.3 & 30.1 & 438 & - & 37.7 & 60.6 \\
\hline
\end{tabular}

$* \sigma_{\mathrm{b}}=$ ultimate tensile strength; $\sigma_{\mathrm{s}}=0.2 \%$ yield strength;

$\delta=\%$ elongation; $\psi=\%$ reduction area

Figure 12 shows the selected multiple step aging treatments' microstructures and fractographic observations. Heat treatment A has many small acicular $\alpha-\mathrm{Cr}$ precipitates, and intergranular cracking is obvious. While heat treatment $\mathrm{B}$ gets less fine, yet uniform $\alpha-\mathrm{Cr}$ particles, and the fractographic character shows more ductility. Therefore, this heat treatment is imposed but not finalized. There are other related issues to be addressed in further research.

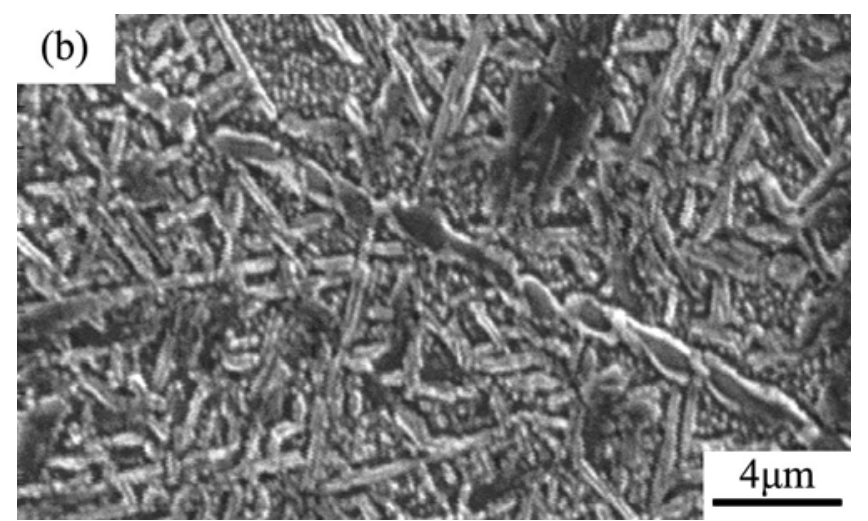

Figure 10. SEM images of $\alpha$-Cr phase in GH837 after $1200^{\circ} \mathrm{C} / 30 \mathrm{~min} / \mathrm{WQ}$ solution + multi-aging treatments

(a) $\mathrm{GH} 837,1140^{\circ} \mathrm{C} / 30 \mathrm{~min} / \mathrm{WQ}+900^{\circ} \mathrm{C} / 16 \mathrm{~h} / \mathrm{WQ}$

(b) $\mathrm{GH} 837,1140^{\circ} \mathrm{C} / 30 \mathrm{~min} / \mathrm{WQ}+900^{\circ} \mathrm{C} / 16 \mathrm{~h} / \mathrm{WQ}+800^{\circ} \mathrm{C} / 200 \mathrm{~h} / \mathrm{WQ}$

* corresponding HT condition in Table $\mathrm{V}$ 

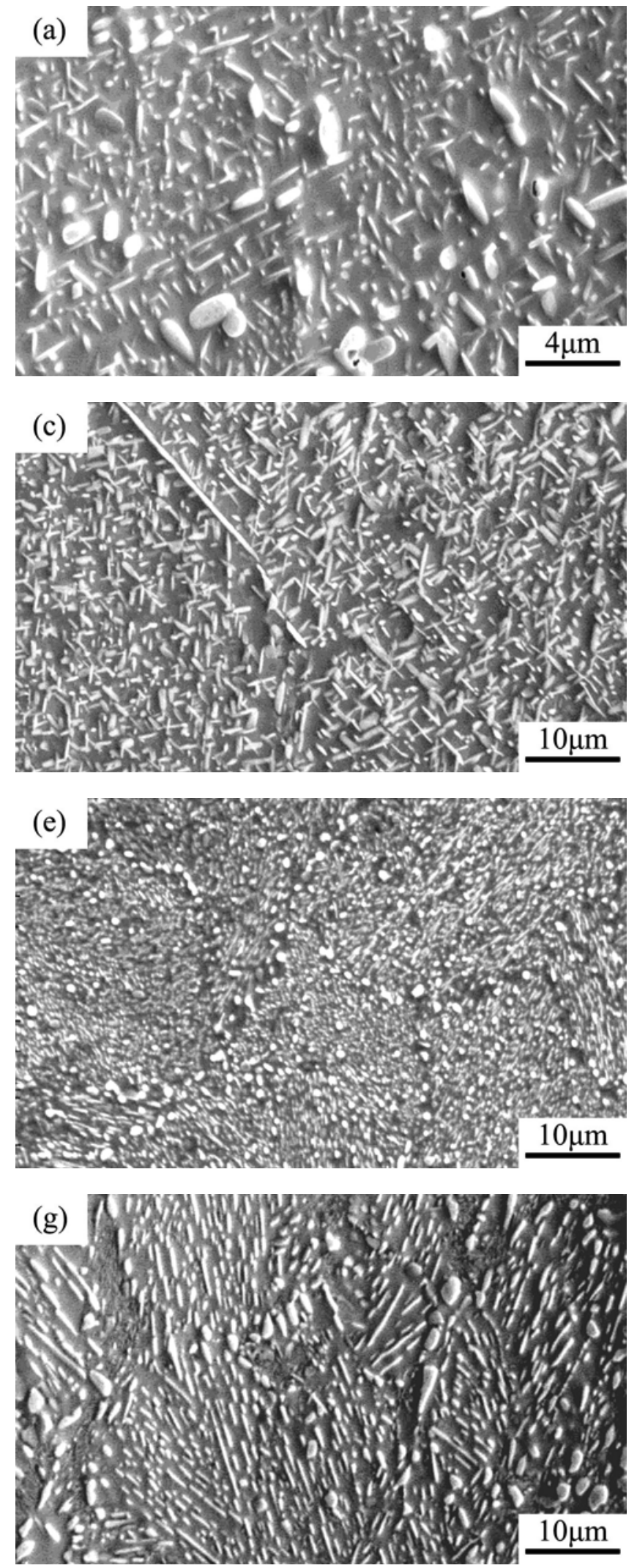
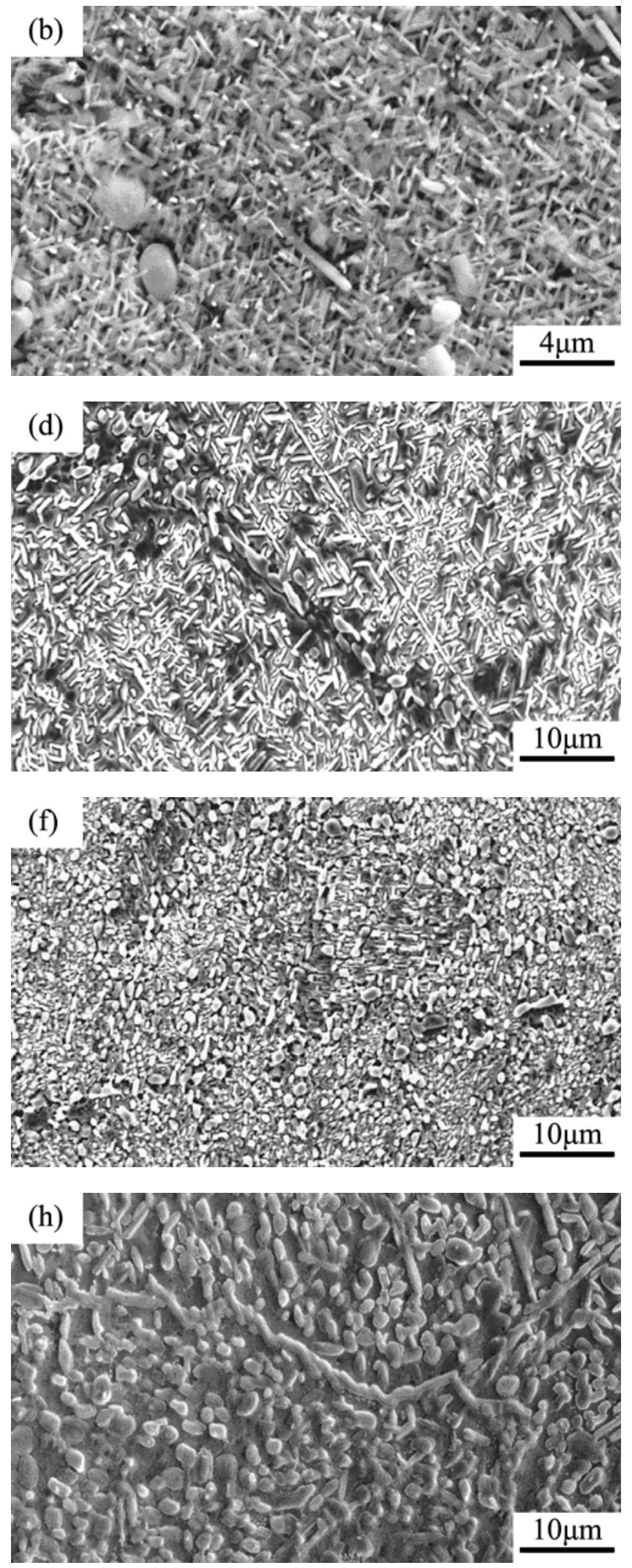

Figure 11. SEM images of $\alpha$-Cr phase in GH840 after solution +multiple step aging treatments *corresponding HT condition in Table V 

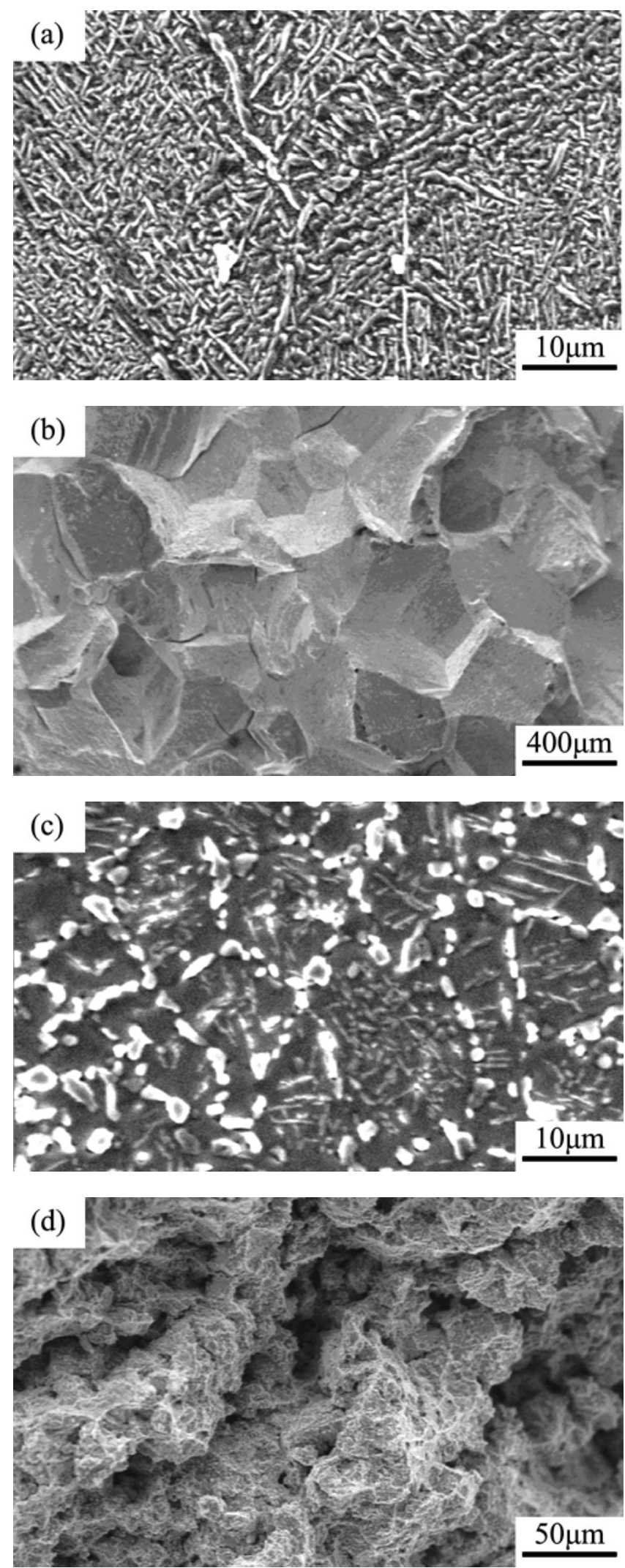

Figure 12. SEM images of microstructure and fractograph of GH837 after two heat treatments A (a),(b) and B (c),(d)

\section{Thermal Processing Capability}

Forge processing properties of high-Cr alloys can be quite poor. In order to examine this phenomenon and mechanism, GH840 samples were deformed by a Gleeble 1500 machine at different temperatures, strains and strain rates to simulate the hot forging behavior. These tests were supplement with the analysis of microstructure and processing.

Figure 13 shows the plot of peak flow stress and compression temperature in the tested alloy $\mathrm{GH} 840$. As for other $\mathrm{Ni}-\mathrm{Cr}$ alloys, flow stress decreased with increasing temperature. However, Figure 14 shows in photos of two groups of specimens after $70 \%$ deformation $(0.1 / \mathrm{s} ; 1 / \mathrm{s})$ that the thermal plasticity declines as temperature increases. This phenomenon is inconsistent with results for lower $\mathrm{Cr}$ cast or wrought superalloys. There existed a high-temperature low-plasticity (HTLP) region of this high $\mathrm{Cr}$ alloy, GH840.

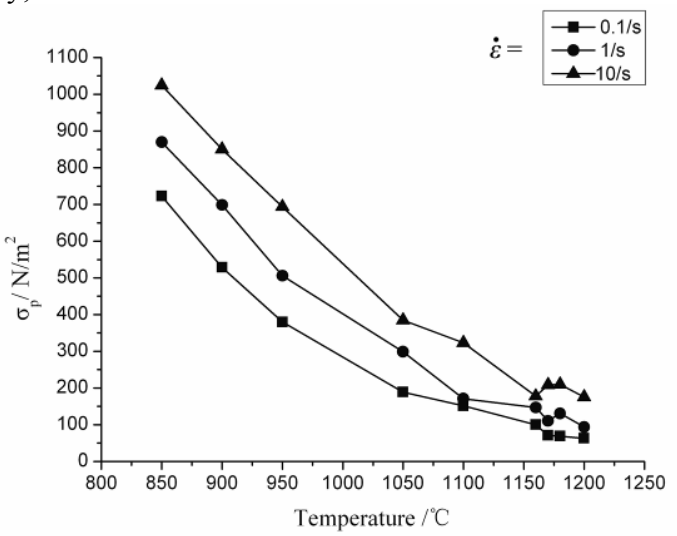

Figure 13. Plot of flow stress peak and compression temperature in GH840

The HTLP phenomenon was also observed for other tested samples not shown in Figure 14. Generally, there were few cracks on the surface of specimens after deformation at $900 \sim 1050^{\circ} \mathrm{C}$; but the cracking increases with increasing temperature above $1050^{\circ} \mathrm{C}$. This HTLP phenomenon is very likely indicates low hot-forging ability for this high $\mathrm{Cr}$ alloy.

Microstructural results show that, besides lamellar $\alpha-\mathrm{Cr}$, a kind of irregular blocky $\alpha-\mathrm{Cr}$ phase directly precipitated from liquid at interdendritic regions. Figure 15(a) is the SEM image of sample after $70 \%$ deformation test at $800^{\circ} \mathrm{C}$. It is obvious that the crack propagates along the blocky $\alpha-\mathrm{Cr}$ phase boundary. It appears that the blocky $\alpha-\mathrm{Cr}$ phase promotes the crack formation.

As temperature increases above $1000^{\circ} \mathrm{C}$, a $\mathrm{Cr}$-depleted region appears around the blocky $\alpha-\mathrm{Cr}$ phase (Figure 15(b, c)) and becomes wider. This region is $\gamma$ matrix phase where the lamellar $\alpha-\mathrm{Cr}$ around the blocky $\alpha-\mathrm{Cr}$ phase is absent.

The Cr-depleted region plus the blocky $\alpha-\mathrm{Cr}$ associated the HTLP phenomenon, and result in non-uniform deformation. As shown in Figure 15(c), the hardness of Cr-depleted region(B) is much lower than blocky $\alpha-\operatorname{Cr}(\mathrm{C})$ and lamellar $\alpha-\operatorname{Cr}(\mathrm{A})$. As the channel of crack propagation (Figure 15 (b)), this region appears to promote and accelerate crack formation and propagation. Deep research work and how to avoid this HTLP in order to increase the forge ability for this type high-Cr superalloy need further keep working. Additional research is required for mechanism of these regions and the HTLP, for increased forging capability. 
$\dot{\varepsilon}=0.1 / \mathrm{s}$

$\dot{\varepsilon}=1 / \mathrm{s}$

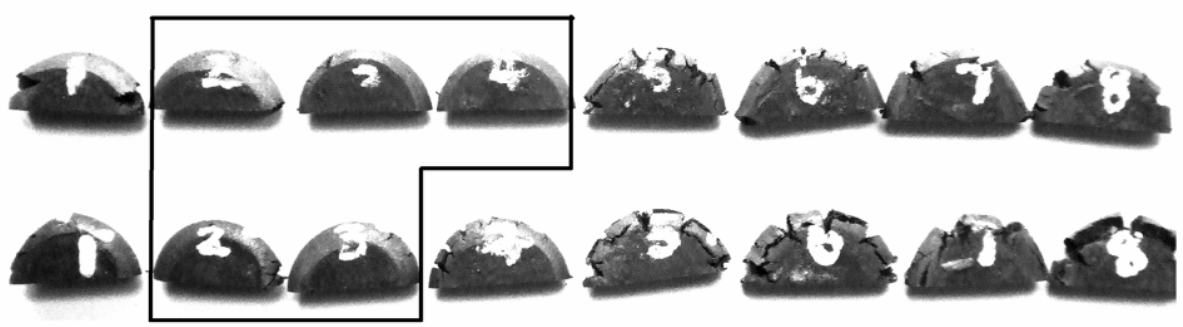

Figure 14. Photos of specimens after compression tests to $70 \%$ deformation
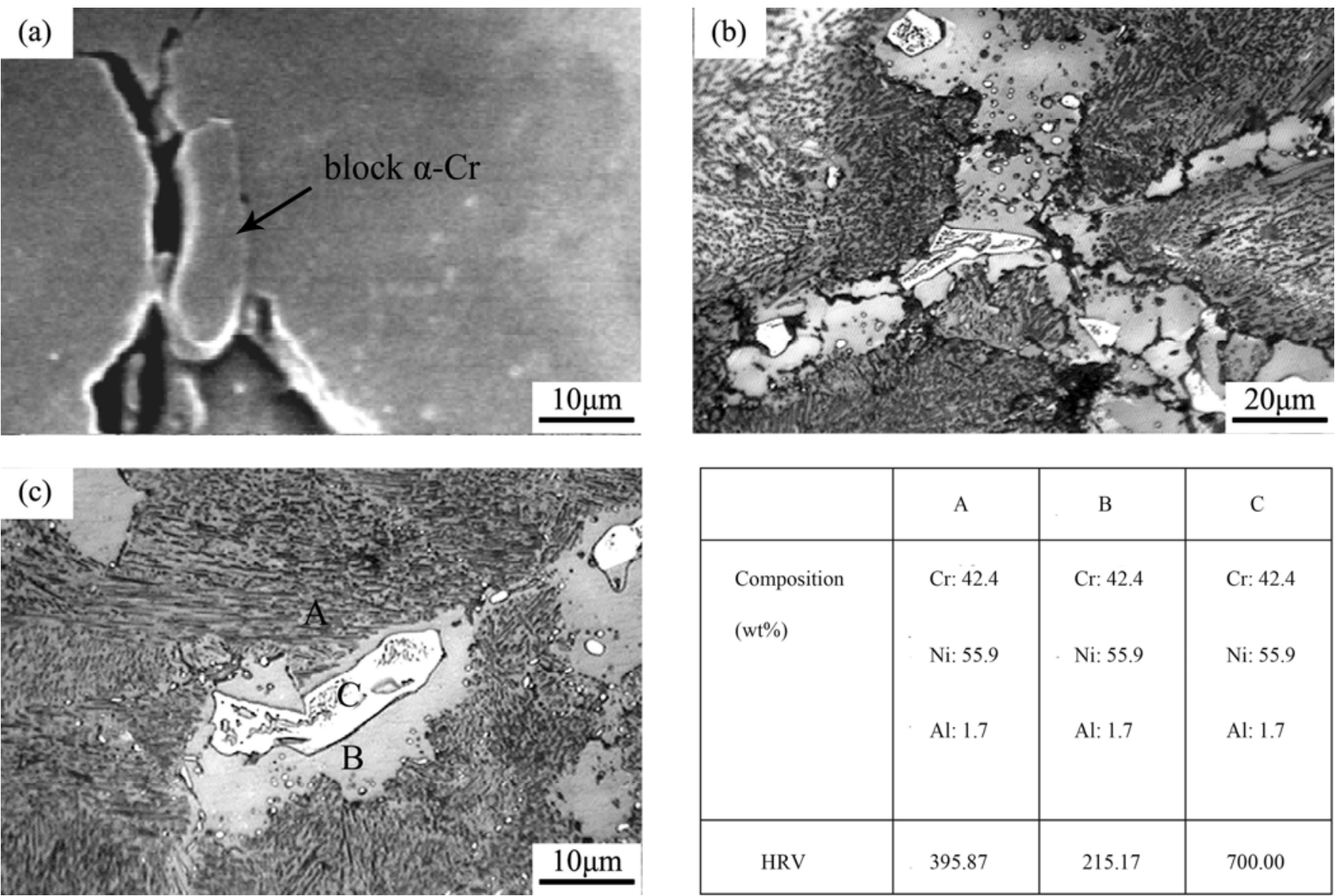

\begin{tabular}{|l|c|c|c|}
\hline & A & B & C \\
\hline Composition & Cr: 42.4 & Cr: 42.4 & Cr: 42.4 \\
& Ni: 55.9 & Ni: 55.9 & Ni: 55.9 \\
& Al: 1.7 & Al: 1.7 & $\mathrm{Al}: 1.7$ \\
& & & \\
\hline HRV & 395.87 & 215.17 & 700.00 \\
\hline
\end{tabular}

Figure 15. Images of block $\alpha$-Cr phase and $\mathrm{Cr}$-depleted region in $\mathrm{GH} 840$ after deformation tests at different temperatures (a) $800^{\circ} \mathrm{C}, \mathrm{SEM}(\mathrm{b}) 1160^{\circ} \mathrm{C}, \mathrm{OM}$ (c) $1160^{\circ} \mathrm{C}, \mathrm{OM} \&$ micro hardness of the different regions

\section{Conclusions}

(1) For high-Cr superalloys GH648, GH837 and GH840, $\alpha-\mathrm{Cr}$ was the main precipitation phase during cooling. It precipitates directly from the austenitic matrix with various morphologies, which were sensitive to composition changes and thermal treatments.

(2) Although $\alpha-\mathrm{Cr}$ precipitation behavior is complex, optimization of $\alpha-\mathrm{Cr}$ precipitation and distribution can be obtained with proper heat treatments. This optimized structure has high stability, and produces high mechanical performance.

(3) There is a high temperature low plasticity (HTLP) phenomenon for the GH840 alloy during deformation. Irregular blocky $\alpha-\mathrm{Cr}$ phase precipitates from the liquid with a Cr-depleted region, which appeared responsible for the HTLP phenomenon. 


\section{Acknowledgement}

The authors appreciate the financial support from National Natural Science Foundation of China, No. 50571015.

\section{References}

1. X. Q. Huang, H. K. Li, Superalloy handbook, (Beijing: Metallurgical industry publishing company China, 2000), 43.

2. S. Y. Lu, X. F. Kang, Nickel and Ni-Fe based corrosion resistant alloys, (Beijing: Chemistry publishing company China, 1989), 67.

3. G. L. Wang, C. W. Wu, M. C. Zhang, J. X. Dong and X. S. Xie, "The Microanalysis of Precipitation Behavior of $\alpha-\mathrm{Cr}$ in Incone1718," Rare Metal Materials Engineering, 31(1)(2002), 3740.

4. X. F. Yan, H. P. Ma, Y. X. Lu and W. S. Liu, "Effect of Cr Content on Microstructure and Mechanical Properties of GH648 alloy," Journal of Materials Engineering, 2002, no. 3: 28-31.

5. G. L. Wang, C. W. Wu, M. C. Zhang, J. X. Dong, X. S. Xie, J.F. Radavich, B. A. Lindsley and G. S. Shen, "The microstructural changes and their effect on CCGR after long time thermal exposure in DA718 and STD718," Materials Science and Engineering, 358 (A)(2003), 71-75.

6. G. L. Wang, C. W. Wu, J. X. Dong and X. S. Xie, "A Research Progress of $\alpha-\mathrm{Cr}$ Phase Precipitation in IN718," Journal of Materials Engineering, 2001, no. 6: 44-47.

7. J. X. Dong, X. S. Xie, “ $\alpha-C r$ Precipitation Behavior and Its Effect on High Cr-Containing Superalloys," ACTA METALLURGICA SINICA, 41(11)(2005), 1159-1166.

8. X. S. Xie, G. L. Wang, J. X. Dong and C. W. Wu, " $\alpha-C r$ Formation in Alloy 718 and Its Effect on Creep Crack Propagation," Superalloys 718, 625, 706 and Various Derivatives, (Pittsburgh, PA: The Minerals, Metals \& Materials Society, 2001), 399-410.

9. N. D. Evans, P. J. Maziasz and J. J. Truhan, "Phase Transformations During Service Aging of Nickel Based Superalloy Pyrome 31V," Solid-Solid Phase Transformations in Inorganic Materials '05, (Pittsburgh, PA: The Minerals, Metals \& Materials Society, 2004), 809-817.

10. J.F. Radavich, "Effect of Alpha Chromium on Long Time Behavior of Alloy 718," Superalloys 718, 625, 706 and Various Derivatives (Pittsburgh, PA: The Minerals, Metals \& Materials Society, 1997), 409-415.

11. J. X. Dong, M. C. Zhang and Y. P. Zeng, "Thermodynamic Calculation of Precipitation Phases in a High-Cr GH648 Superalloy," Rare Metal Materials and Engineering, 34, (1)(2005), 51-55.

12. Y. Han, J. X. Dong, Y. P. Zeng and M. C. Zhang, "Comparison of Microstructure and Properties between Two High
Chromium Ni-Cr Base Superalloys," Journal of the Chinese Rare Earth Society, 23(2005), 152-157.

13. S. Y. Zhang, New hand book of metal materials, (Beijing: Chinese Technology and Culture publishing company, 2005), 170. 